\title{
Kernos
}

Revue internationale et pluridisciplinaire de religion

grecque antique

$11 \mid 1998$

Varia

\section{L'Empereur Julien, Contre les Galiléens. Une imprécation contre le christianisme, Intr., trad. et comm. par Christopher GÉRARD}

\section{André Motte}

\section{OpenEdition}

\section{Journals}

Édition électronique

URL : http://journals.openedition.org/kernos/1265

DOI : 10.4000/kernos. 1265

ISSN : 2034-7871

\section{Éditeur}

Centre international d'étude de la religion grecque antique

\section{Édition imprimée}

Date de publication : 1 janvier 1998

ISSN : 0776-3824

\section{Référence électronique}

André Motte, «L'Empereur Julien, Contre les Galiléens. Une imprécation contre le christianisme, Intr., trad. et comm. par Christopher GérARD », Kernos [En ligne], 11 | 1998, mis en ligne le 21 avril 2011, consulté le 24 septembre 2020. URL : http://journals.openedition.org/kernos/1265 ; DOI : https://doi.org/ 10.4000/kernos. 1265 
un «fossile », en sous-estimant l'effort d'organisation du savoir mythique, en particulier par le biais du schéma généalogique, tout comme ce fut le cas dans la Théogonie d'Hésiode.

On l'aura compris: ces deux livres parus presque coup sur coup sur la Bibliothèque d'Apollodore ne font assurément pas double emploi. Chacun répond à un objectif différent et contribue, à sa façon, à relancer l'intérêt pour le discours mythologique dans la culture grecque.

\section{Corinne Bonnet \\ (FNDP Namur - Pontificio Istituto Biblico)}

Yves LehmanN, Varron théologien et philosophe romain, Bruxelles, 1997. 1 vol. $16 \times 24,5 \mathrm{~cm}, 394$ p. (Coll. Latomus, 237). ISBN : 2-87031-177-X.

Issu d'un doctorat d'État soutenu en Sorbonne en mars 1993, cet ouvrage de belle tradition universitaire française rend pleinement grâce à l'œuvre de Varron, tout en esquissant de l'homme un portrait qui va se précisant au fil de la lecture.

Après une introduction qui montre notamment ce que la reconstruction dumézilienne de la religion romaine archaïque doit à la synthèse de toute la structure idéologique et religieuse de la romanité tentée par Varron, trois parties bien équilibrées rythment l'exposé : la première retrace l'itinéraire spirituel d'un homme marqué par ses origines sabines et formé à diverses sources de savoir et d'expérience; la deuxième - qui intéressera tout particulièrement l'historien des religions - analyse le système théologique de Varron (religion et politique; «tripartition divine "; problème des statues divines; theologia tripertita; polythéisme et monothéisme; regard sur les religions orientales); la troisième envisage sa doctrine philosophique. Cet itinéraire replace bien l'érudit dans une koinè philosophique et théologique "d'élaboration gréco-hellénistique ".

La « religion » de Varron consiste en « un subtil dosage de cosmicité et de romanité », un équilibre qui s'ancre à la fois dans son souci de la chose publique et des traditions de l'Urbs, et dans le dépassement d'un cadre cultuel qu'il ne combat pas, mais que son exigence intellectuelle le conduit à dépasser. Ainsi, l'A. rend une cohérence à ce que l'on a trop souvent taxé d'inconséquence dans l'œuvre de Varron, par l'analyse fine et nuancée d'une pensée en recherche de vérité, «à mi-chemin de l'idéalisme pur et du réalisme le plus froid et le plus calculateur $»$. On pourra simplement regretter l'usage peut-être abusif de la notion de «monothéisme » pour définir l'aboutissement de la démarche religieuse et philosophique de Varron (p. 226-242). Il eût été souhaitable d'insérer cette réflexion dans un cadre théorique plus large; on aurait notamment voulu voir apparaître l'important ouvrage de H.S. VERSNEL sur l'hénothéisme, un terme que l'A. utilise aussi, mais comme une simple variatio sermonis de "monothéisme » (Inconsistencies in Greek and Roman Religion. 1. Ter Unus. Isis, Dionysos, Hermes. Three Studies in Henotbeism, Leiden, Brill, 1990).

Vinciane Pirenne-Delforge (Université de Liège)

L'Empereur Julien, Contre les Galiléens. Une imprécation contre le christianisme, Intr., trad. et comm. par Christopher GÉRARD. Postface par L. Couloubaritsis, Bruxelles, Ousia, 1995: 1 vol. $14 \times 21 \mathrm{~cm}, 183$ p. ISBN : 287060-047-X.

Cet ouvrage de Julien n'avait plus été traduit en fançais depuis le siècle dernier. On félicitera donc l'A. d'avoir entrepris ce travail et de produire ici non 
seulement une traduction visant la plus grande fidélité au texte, mais aussi un commentaire assez fouillé ainsi qu'une introduction rappellant brièvement l'itinéraire spirituel de l'auteur et l'histoire de la polémique anti-chrétienne qui a précédé son essai. Je laisserai aux historiens spécialistes le soin d’apprécier la pertinence de certaines positions défendues, mais j'observe que l'étude est fondée sur l'exploitation d'une bibliographie abondante et bien à jour. La contribution de L. Couloubaritsis ajoute une intéressante mise en perpective, philosophique et politique, des idées exposées par Julien; y sont notamment abordées la question de l'universalité que l'empereur refuse de reconnaître au christianisme et son attitude ambiguë à l'égard du mythe; la conclusion souligne, dans une réflexion actualisée, la difficulté et les enjeux des rapports entre religion et politique.

Au total, l'ouvrage contribuera à mieux faire connaître cette œuvre de Julien et à en faire voir l'importance; il s'agit à l'évidence d'un essai de réhabilitation, mais une telle démarche, est-il bien précisé (p. 149, n. 18), n'équivaut aucunement à une apologie des idées défendues par l'empereur.

André Motte

(Université de Liège)

Jacqueline Duchemin $t$, Mythes grecs et sources orientales, textes réunis par Bernard Deforge, Paris, Les Belles Lettres, 1995, xv+345 p. (Vérité des Mythes). ISBN : 2-251-32422-4.

Si la problématique de l'apport des sources orientales à la formation de la mythologie grecque connaît un grand succès depuis une bonne décennie ( $c f$., notamment, W. BURKerT, The Orientalizing Revolution: Near Eastern Influence on Greek Culture in the Early Archaic Age, Cambridge Mass.-Londres 1992; Ch. PENGLASE, Greek Myths and Mesopotamia. Parallels and Influence in the Homeric Hymns and Hesiod, Londres-New York 1994; A. BERNABÉ, Influences orientales dans la littérature grecque: quelques réflexions de méthode, in Kernos, 8 [1995], p. 9-22, pour les différents aspects de cette problématique, par exemple le rapport entre support écrit, oral et figuré), Jacqueline Duchemin (1910-1988), qui commença à s'y intéresser dès le début des années '50, a véritablement été une pionnière dans ce domaine. Le volume édité par les soins de Bernard Deforge lui rend bien justice et montre toute la cohérence d'un parcours scientifique profondément novateur et orginal. "Greece is a part of Asia; Greek literature is a Near East literature »: telle est l'énoncé, dû à la plume de M.L. West, qui figure au frontispice de ce livre, comme pour provoquer le lecteur, pour l'inciter à se laisser guider sur des sentiers insolites et aussi pour souligner le consensus récemment acquis à l'égard d'une ligne interprétative qui a mis du temps à s'imposer. La Black Atbena de Martin Bernal a suffisamment illustré les résistances idéologiques qui, dans le domaine de l'Altertumswissenschaft, ont favorisé la vision gréco-grecque de la genèse de la mythologic, à laquelle on a appliqué le schéma du fameux «miracle » grec, comme à toutes les formes d'expression culturelle de cette civilisation.

L'œuvre de J. Duchemin, comme l'indique bien la Préface de B. Deforge et $\mathrm{P}$. Thiercy, suit une «ligne de recherche permanente et essentielle » qui encourage le décloisonnement disciplinaire et culturel, en traçant notamment un axe triangulaire d'échanges Grèce (Argos en particulier) - Égypte - Phénicie, avec, pour ce qui concerne le monde hellénique, trois «têtes de pont » principales, à savoir Hésiode, Pindare et Eschyle. On doit se rappeler que la découverte des mythes ougaritiques d'une part et des mythes hittito-hourrites de l'autre, dans les décennies qui précédèrent et suivirent immédiatement la $\mathrm{Il}^{\mathrm{e}}$ Guerre Mondiale, 